\title{
Training of Traditional Birth Attendants on Prevention of Mother to Child Transmission of HIV: Effect on Their Knowledge and Delivery of Prevention of Mother to Child Transmission of HIV Services in Igbagu, Ebonyi State Nigeria
}

\author{
A. F. Una ${ }^{1 *}$, L. U. Ogbonnaya ${ }^{1}$, C. N. Obionu ${ }^{2}$, K. N. Omeje ${ }^{3}$ and E. I. Obi ${ }^{1}$ \\ ${ }^{1}$ Department of Community Medicine, Federal Teaching Hospital, Abakaliki, Ebonyi State, Nigeria. \\ ${ }^{2}$ Department of Community Medicine, University of Nigeria, Enugu Campus, Enugu State, Nigeria. \\ ${ }^{3}$ Department of Paediatric, Federal Teaching Hospital, Abakaliki, Ebonyi State, Nigeria.
}

Authors' contributions

This work was carried out in collaboration between all authors. Author AFU designed the study, performed the statistical analysis and wrote the first draft of the manuscript. Authors AFU, LUO and

CNO wrote the protocol. Author AFU managed the analyses of the study. Authors KNO and

EIO managed the literature searches. All authors read and approved the final manuscript.

Article Information

DOI: $10.9734 / \mathrm{ACRI} / 2017 / 34390$

Editor(s):

(1) Imran Aslan, Bingol University, Bingol, Turkey.

Reviewers:

(1) Bernadette Ngo Nonga, University of Yaounde I, Cameroon.

(2) Sadandaula Rose Muheriwa, University of Malawi-Kamuzu College of Nursing, Malawi. Complete Peer review History: http://www.sciencedomain.org/review-history/19970

Original Research Article

Received $25^{\text {th }}$ May 2017

Accepted $3^{\text {rd }}$ July 2017

Published $10^{\text {th }}$ July 2017

\section{ABSTRACT}

Aims: To assess the traditional birth attendants' (TBAs') knowledge of HIV and prevention of mother to child transmission (PMTCT) of HIV and their practice of PMTCT of HIV services delivery. It was also designed to train them on PMTCT of HIV and mobilization of the pregnant women in the community to access PMTCT of HIV services in a formal health facility.

Study Design: The study was a cross-sectional descriptive study with an interventional component

Place and Duration of Study: The 8 months study was conducted in Igbagu Community in Izzi Local Government Area of Ebonyi State Nigeria, in 2015. 


\begin{abstract}
Methodology: A total population study of all TBAs in the study area identified using the snowball non-probabability sampling method was conducted. Baseline assessment of their knowledge and practice of PMTCT of HIV services delivery was done. They were subsequently trained on PMTCT of HIV and on mobilization and referral of pregnant women to access HIV counselling and testing (HCT) and other PMTCT of HIV services at a designated health facility in the community. At the end of the study, post training PMTCT of HIV knowledge assessment and determination of the number of pregnant women who complied with the TBAs' referral for PMTCT of HIV serices at the health facility were carried out.

Results: Assessment of the TBAs' composite knowledge of modes of HIV transmission and preventive measures gave the mean score of $14.8 \% \pm 11.5 \%$ and $68.8 \% \pm 12.5 \%$ pre and post training respectively. The difference was statistically significant $(Z=-5.2 ; p<0.001)$. Following the training, all the TBAs were referring their clients to health facility for PMTCT of HIV services compared to $10(28.6 \%)$, before the study. Fifty two pregnant women complied with referral by the TBAs to the health facility for PMTCT of HIV services out of the 129 pregnant mothers who visited them during the study, giving a compliance rate of $40.3 \%$
\end{abstract}

Keywords: TBAs; training; PMTCT uptake; Ebonyi State; Nigeria.

\section{INTRODUCTION}

In 2010, the Nigerian National Agency for the Control of AIDS (NACA) and partners reported that Nigeria had the second highest number of people living with HIV (2.98 million) in terms of prevalence $(3.6 \%)$ in sub-Saharan Africa, making about $9 \%$ of global burden. Women were more affected in the defining feature of the epidemic in sub region $[1,2]$.

HIV transmission from an infected mother to child during pregnancy, delivery or breastfeeding is known as Mother-to-Child Transmission (MTCT) of HIV and interventions to prevent such transmission is known as Prevention of Mother to Child Transmission (PMTCT) of HIV. MTCT of HIV has been recognized as a major public health problem world over and its increasing prevalence especially in the developing countries requires a concerted effort to stem the tide in all epidemic settings [1]. In 2009 report by World Health Organization (WHO) showed that more than $90 \%$ of HIV infections occurring in children were acquired through MTCT [3]. The Nigerian National Guideline on Prevention of Mother to Child Transmission of HIV stated that the risk of such transmission is between $30 \%-40 \%$ in the absence of any intervention. The document also pointed out that uptake of PMTCT services in Nigeria was low in spite of significant advances in HIV/AIDS treatment and care [4].

In a survey jointly carried out by the United States Agency for International Development (USAID), Federal Ministry of Health and National Agency for the Control of AIDS (NACA), in 2008, it was reported that $88 \%$ of state-run health facilities offer HCT services. There were however much lower levels of availability for PMTCT (25\%). The availability of all HIV/AIDS services was lower in rural than in urban areas [5]. This being as a result of inadequate health workers trained to render PMTCT services. Therefore there is the need to take such services to these rural areas using trianed health workers in the formal health facility in functional collaboration with the informal health care workers such as the TBAs.

A TBA is defined as a person who assists mothers during childbirth and initially acquired his/her skills by delivering babies him/herself or through apprenticeship to other TBA [4]. A 2010 document of the Nigerian Federal Ministry of Health showed that in 2008, TBAs assisted 22\% of births while skilled birth attendants attended to the $39 \%$ of pregnant women in the same year [6]. Since TBAs attend to a substantial proportion of pregnant women, involving them in PMTCT of HIV interventions may have a significant positive effect on reducing MTCT of HIV. A study carried out to assess the role of traditional birth attendants (TBAs) in modern health care delivery in Edo State, Nigeria, revealed that child bearing mothers patronize TBAs because their services were cheap, readily accessible/available and were near to the grassroots [7]. As a result, these TBAs could be effectively used to mobilize community support for PMTCT of HIV and to persuade pregnant women in rural communities to access comprehensive PMTCT of HIV services in formal health facilities.

In order to achieve the national goal and targets of 2010 - 2015 PMTCT scale up plan, the 
Nigerian National PMTCT of HIV Guideline of 2010 recommended community-based PMTCT of HIV among other interventions aimed at reduction of MTCT of HIV. Community-based PMTCT of HIV involves the provision of PMTCT services by formal (trained health personnel) or informal care providers such as TBAs, outside the hospital settings usually within communities [4].

However, studies have shown that these TBAs have little or no knowledge of HIV, its mode of transmission, and that it could be transmitted from mother to child [8-11]. The same applies to their knowledge of PMTCT of HIV and the benefits of PMTCT of HIV services delivery to the pregnant women. This was shown by a study in rural area of Calabar, Nigeria in which it was revealed that out of 140 TBAs interviewed in 2007, 23.6\% had never had any information concerning HIV/AIDS from any source [8]. This underscores the need to also give the TBAs information and training on issues related to HIV and on mobilization of pregnant women to access PMTCT of HIV services in health facilities.

TBAs' training in Lagos State Nigeria, Zimbabwe and in Cameron respectively resulted in improved HIV/PMTCT of HIV knowledge and services delivery [12-14]. Therefore, training the TBAs especially those in a rural community (where there is relative shortage of health facility workerrs), on PMTCT of HIV and using them in the mobilization, HIV/PMTCT of HIV counselling as well as referral of pregnant women to health facilities would increase the pregnant women's access to the services. This will also reduce morbidity burden on the public health system and improve the health of the general public.

The National PMTCT of HIV guideline of 2010 reorgnized that TBAs lack adequate knowledge on issues relating to reproductive health, STIs and HIV/AIDS and therefore pointed out the imperative of training these informal cadre of community health resource persons to ensure a HIV/AIDS-free future generation. The policy document further reommended a community collaborative work that would improve referral practices between TBAs and formal health facilities [4].

This study was undertaken to assess the TBAs' knowledge of HIV and PMTCT of HIV and their practice of PMTCT of HIV services delivery. It was also designed to train them on PMTCT of
HIV and on mobilization of the pregnant women in the community in order to access comprehensive PMTCT of HIV services in a formal health facility using a functional referral system.

\section{METHODOLOGY}

\subsection{Study Area}

The study was conducted in the rural communities of Igbagu in Izzi Local Government Area of Ebonyi State (South Eastern Nigeria) between April and November 2015. Igbagu shares boundaries with Cross River State in the east, Ikwo Local Government Area in the south, Nnodo community in the north (both in Ebonyi State) and Abakaliki state capital in the west. Igbagu has four communities with a population of 22,855 [15]. People of Igbagu are agrarian, growing mainly root crops and grains especially rice. Choice of this setting was purposive because the community is host to the only public health centre with the capacity to offer comprehensive HIV services in terms of human and material resources in a rural setting of the state as at the time of the study. The health facility is a model health centre being the community health practice centre for a teaching hospital in the state.

\subsection{Study Design}

The study which was cross-sectional and descriptive in design with an intervention component involved all the TBAs in the study area. It comprised of HIV/PMTCT of HIV pre and post training knowledge assessment with an intervening training on HIV/PMTCT of HIV. Assessment of PMTCT of HIV services delivery by the TBAs and of utilization of PMTCT of HIV services at a health facility by pregnant women following their mobilization by the trained TBAs after the training were also carried out. The study lasted for 8 months within which the identification and enrolment of TBAs and activities around the training lasted for 2 months. Follow up of the TBAS and post intervention evaluation took the remaining six months.

\subsection{Sampling Method}

Being a total population study, all the TBAs in the community were identified and enrolled. Thirty seven TBAs were identified using the snowball non-probability sampling method. A sensitization/introductory meeting was held with 
all the indentified TBAs in attendance. During the meeting, the aim of the study was explained to the TBAs and their involvement was solicited. They were reminded that their particiption shall contribute to the control of MTCT of HIV in their community. They were also assured that their job as TBA would not be interfered with. All the TBAs acccepted to participate and written informed consents were obtained from them subsequently before enrolment into the study.

\subsection{Study Instrument}

A pretested, interviewer-administered, double language translated structured questionnaires were used to collect information from the TBAs. Pre-training data on their knowledge and practice of PMTCT of HIV was collected at baseline. Seven questions were used to assess PMTCT of HIV knowledge. These questions centred on modes of HIV transmission, its prevention, MTCT of HIV and the risk reduction measures. In order to determine their practice of PMTCT of HIV services delivery, the TBAs responded to questions on frequency of their referring client to health facility for PMTCT of HIV, efforts they made to find out clients and their spouse's utilization of HCT services and counseling of their pregnant clients.

\subsection{TBA Training}

A 3 - working day training sessions on HIV/PMTCT of HIV care and support was organized for TBAs in the four respective villages in the community. A WHO PMTCT of HIV generic training module was adapted for the training [16]. Emphasized during the training was the mobilization of pregnancy women to access PMTCT of HIV services in the health facility. The TBAs were also taught how to keep records of their clients and to offer to all of them referral to a desgnated health facility where PMTCT of HIV services was established during the study in the community in order to access PMTCT of HIV services. They were issued with tallies which they gave to pregnant women on referral who in turn submitted same at the receiving health facility. The submitted tally enabled the researchers determine the number of pregnant women referred by the TBAs and those who eventually complied. These information were collated from the health facility and TBAs' records respectively. The TBAs were also encouraged to accompany the pregnant women to encourage compliance. Post intervention data were collected during the last meeting with TBAs to assess improvement in their practice of PMTCT of HIV services delivery relative to their pre-training practices. Also record of client referral to health facilities was collected both from the TBAs and the records of the receiving health facility.

\subsection{Data Management and Analysis}

The generated data were entered into the computer using the statistical package for social scientists (SPSS), for window version 20 [17]. Descriptive analysis and statistical tests of significance were done and reported using the same software. TBAs' knowledge of PMTCT of HIV was assessed using 29 questions grouped into 7 domains. A composite knowledge score was constructed by summing up responses to the knowledge questions. Each correct response earned 1 point and wrong answers had no point. The scores were converted to percentage and graded into two; inadequate and adequate knowledge; score $<50 \%$ constituted inadequate knowledge while those scoring $\geq 50 \%$ had adequate PMTCT of HIV knowledge. Comparison of pre and post training knowledge of PMTCT of HIV was done using Chi square test (for graded knowledge), and Wilcoxon signed rank test (for composite knowledge scores). Results were presented on tables and a figure.

\section{RESULTS AND DISCUSSION}

\subsection{Results}

A total of 37 TBAs were identified in Igbeagu Development Centre and recruited into the study. However, 2 (5.4\%), TBAs could not complete the training and subsequent follow up activities and were excluded in the analysis.

Table 1 shows that all the TBAs were females and $34(97.1 \%)$, were above 40 years of age. Only $1(2.9 \%)$, had formal education up to secondary school. Majority, 26 (74.3\%) of them combine their trade as TBAs with farming. Except for one TBA who acquired her skill in a private hospital, all the others had acquired their skill from a family member.

As seen on Table 2, 23 (65.7\%) TBAs were aware of MTCT of HIV at baseline. There was $100 \%$ awareness of HIV, HCT and PMTCT of HIV following the training. The improvements in the TBAs' awareness of HIV, HCT and PMTCT of HIV after the training were statistically significant $(P<0.05)$. 
Table 1. TBAs' socio - demographic characteristics

\begin{tabular}{llll}
\hline Socio - demographic variables & $\mathbf{N}=\mathbf{3 5}$ & Proportion (\%) \\
\hline Age (years) & Below 40 & 1 & 2.9 \\
\multirow{2}{*}{ Educational status } & Above 40 & 34 & 97.1 \\
\multirow{3}{*}{ Other occupations } & No formal education & 34 & 97.1 \\
& Completed senior secondary & 1 & 2.9 \\
& Herbalists & 6 & 17.1 \\
Religion & Petty traders & 3 & 8.6 \\
& Farmers & 26 & 74.3 \\
Apprenticeship & Christian & 31 & 88.6 \\
& African Traditional religion & 4 & 11.4 \\
& Familial inheritance & 34 & 97.1 \\
\hline
\end{tabular}

Table 2. Awareness of HIV/HCT/PMTCT of HIV for the TBAs at baseline and after intervention

\begin{tabular}{llll}
\hline Variable & \multicolumn{2}{c}{ Number and percentage of HCT } & $\boldsymbol{X}^{2}$ test [ $(\boldsymbol{P}$-value $\left.)\right]$ \\
\cline { 2 - 3 } & $\begin{array}{l}\text { Before training } \\
\mathbf{N}=\mathbf{3 5}(\%)\end{array}$ & $\begin{array}{l}\text { After training } \\
\mathbf{N}=\mathbf{3 5}(\%)\end{array}$ & \\
\hline Ever heard about HIV & $29(82.9)$ & $35(100)$ & $6.56(0.03)$ \\
Ever heard about HCT & $26(74.3)$ & $35(100)$ & $10.33(0.001)$ \\
Ever heard about PMTCT of HIV & $23(65.7)$ & $35(100)$ & $14.48(<0.001)$ \\
\hline
\end{tabular}

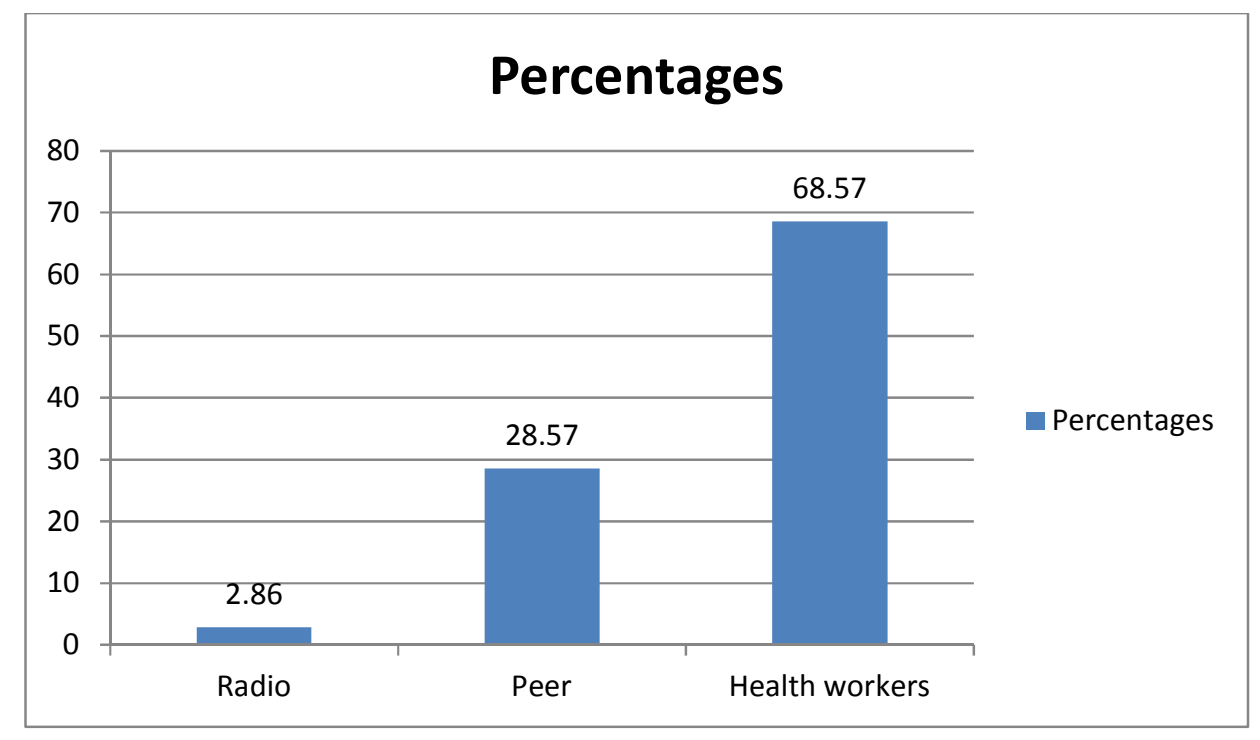

Fig. 1. TBAs sources of information on PMTCT of HIV

Fig. 1 above shows that health workers were the main source of information on HIV, HCT and PMTCT of HIV for majority, $24(68.6 \%)$ of the TBAs at baseline. Only one TBA $(2.85 \%)$, had heard about the issues on the radio.

Assessment of knowledge of HIV/PMTCT of HIV revealed that the TBAs' knowledge of different issues regarding HIV/PMTCT of HIV was very low. Unprotected sexual intercourse was the commonest mode of HIV transmission known to the TBAs. Three (8.6\%) knew MTCT of HIV and transmission of HIV through unsafe blood tranfusion respectively. Transmission of HIV through sharing of sharp instruments was known to $12(34.4 \%)$ of them. Likewise, abstinence from sexual intercourse as a preventive measure was the most known among the TBAs, (known to $40 \%$ ). Fifty seven percent of them also knew that HIV infection could be confirmed with a screening test. MTCT of HIV during pregnancy was known to $16(45.7 \%)$, while less than $10 \%$ 
knew that it could occur during labour and breastfeeding respectively. MTCT of HIV risk reduction measures were almost unknown to the TBAs except for few of them who knew about ART (11.4\%), seeking good ANC (11.4\%), delivery at health facility $(2.9 \%)$, good management of labour (5.7\%), and avoiding mixed feeding $(2.9 \%)$ as measures that could reduce MTCT of HIV. There were remarkable statistical significant improvements in knowledge in majority of the variables after the training, $(P<0.001)$. Improvements in knowledge of abstinence from sexual intercourse, opting for Caesarean section and avoiding pushing unless instructed as measures for MTCT reduction were not statistically significant $(P>0.05)$. These are shown on Table 3.

Table 3. Responses to questions on HIV/PMTCT of HIV knowledge assessment of TBAs

\begin{tabular}{|c|c|c|c|c|}
\hline \multirow[t]{2}{*}{ Variables } & \multicolumn{3}{|c|}{ Correct responses $\mathbf{N}(\%)$} & \multirow[t]{2}{*}{$X^{2}$ test (P-value) } \\
\hline & $\begin{array}{l}\text { Before } \\
\text { intervention } \\
\mathrm{N}=35\end{array}$ & $\begin{array}{l}\text { After } \\
\text { intervention } \\
\mathrm{N}=35\end{array}$ & df & \\
\hline \multicolumn{5}{|l|}{ Modes of HIV transmission } \\
\hline $\begin{array}{l}\text { Unprotected sexual } \\
\text { intercourse }\end{array}$ & $24(68.6)$ & $35(100)$ & 1 & $13.05(<0.001)$ \\
\hline Mother to child & $3(8.6)$ & $33(91.4)$ & 1 & $48.06(<0.001)$ \\
\hline Unsafe blood transfusion & $3(8.6)$ & $15(42.9)$ & 1 & $10.77(0.002)$ \\
\hline $\begin{array}{l}\text { Sharing of sharp instruments } \\
\text { like needles }\end{array}$ & $12(34.3)$ & $32(91.4)$ & 1 & $24.47(<0.001)$ \\
\hline \multicolumn{5}{|l|}{ Prevention of HIV transmission } \\
\hline $\begin{array}{l}\text { Abstinence from sexual } \\
\text { intercourse }\end{array}$ & $14(40.0)$ & $13(37.1)$ & 1 & $0.06(1.00)$ \\
\hline $\begin{array}{l}\text { Avoid sharing of sharp } \\
\text { instruments }\end{array}$ & $7(20.0)$ & $32(91.4)$ & 1 & $36.19(<0.001)$ \\
\hline $\begin{array}{l}\text { Correct and consistent } \\
\text { condom use }\end{array}$ & $2(5.7)$ & $20(57.1)$ & 1 & $21.48(<0.001)$ \\
\hline $\begin{array}{l}\text { Access to PMTCT of HIV } \\
\text { services }\end{array}$ & $1(2.9)$ & $30(85.7)$ & 1 & $48.69(<0.001)$ \\
\hline Faithfulness to one's partner & $9(25.7)$ & $35(100)$ & 1 & $41.36(<0.001)$ \\
\hline $\begin{array}{l}\text { Screening of blood before } \\
\text { transfusion }\end{array}$ & $1(2.9)$ & $13(37.1)$ & 1 & $12.86(0.001)$ \\
\hline \multicolumn{5}{|l|}{ Knowledge of HCT } \\
\hline $\begin{array}{l}\text { HIV testing confirms } \\
\text { infection }\end{array}$ & $20(57.1)$ & $35(100)$ & 1 & $19.09(<0.001)$ \\
\hline $\begin{array}{l}\text { Healthy person can have } \\
\text { HIV }\end{array}$ & $9(25.7)$ & $33(94.3)$ & 1 & $35.87(<0.001)$ \\
\hline \multicolumn{5}{|l|}{ Period during which MTCT can occur } \\
\hline During pregnancy & $16(45.7)$ & $33(94.3)$ & 1 & $19.70(<0.001)$ \\
\hline During labour & $2(5.7)$ & $27(77.1)$ & 1 & $36.80(<0.001)$ \\
\hline During breastfeeding & $13(8.6)$ & $27(77.1)$ & 1 & $11.43(0,001)$ \\
\hline \multicolumn{5}{|c|}{ Transmission risk reduction measures during pregnancy } \\
\hline $\begin{array}{l}\text { Abstain from unprotected } \\
\text { sex }\end{array}$ & $0(0)$ & $8(22.9)$ & 1 & $9.03(0.005)$ \\
\hline Take ARTs & $4(11.4)$ & $34(97.1)$ & 1 & $51.80(<0.001)$ \\
\hline Safer sex (condom use) & $0(0)$ & $21(60.0)$ & 1 & $30.00(<0.001)$ \\
\hline $\begin{array}{l}\text { Seek ANC with skilled birth } \\
\text { attendant }\end{array}$ & $4(11.4)$ & $30(83.7)$ & 1 & $38.66(<0.001)$ \\
\hline \multicolumn{5}{|c|}{ Transmission risk reduction measures during labour } \\
\hline Elective Caesarean section & $0(0)$ & $12(34.3)$ & 1 & $14.48(<0.001)$ \\
\hline Good labour management & $2(5.7)$ & $7(20.0)$ & 1 & $3.19(0.15)$ \\
\hline Deliver in health facility & $1(2.9)$ & $27(77.1)$ & 1 & $(<0.001)$ \\
\hline $\begin{array}{l}\text { Avoid pushing unless } \\
\text { instructed }\end{array}$ & $0(0)$ & $5(14.3)$ & 1 & $5.38(0.054)$ \\
\hline
\end{tabular}




\begin{tabular}{|c|c|c|c|c|}
\hline \multirow[t]{2}{*}{ Variables } & \multicolumn{3}{|c|}{ Correct responses N (\%) } & \multirow[t]{2}{*}{$x^{2}$ test ( $P$-value) } \\
\hline & $\begin{array}{l}\text { Before } \\
\text { intervention } \\
\mathrm{N}=35\end{array}$ & $\begin{array}{l}\text { After } \\
\text { intervention } \\
\mathrm{N}=35\end{array}$ & df & \\
\hline $\begin{array}{l}\text { Continue ART for HIV } \\
\text { positive women }\end{array}$ & $0(0)$ & $27(77.1)$ & 1 & $43.95(<0.001)$ \\
\hline Avoid prolonged labour & $0(0)$ & $26(74.3)$ & 1 & $41.36(<0.001)$ \\
\hline \multicolumn{5}{|c|}{ Transmission risk reduction measures during breastfeeding } \\
\hline $\begin{array}{l}\text { Breastfeed only and } \\
\text { continue ART }\end{array}$ & $0(0)$ & $28(80.0)$ & 1 & $46.67(<0.001)$ \\
\hline Avoid mixed feeding & $1(2.9)$ & $17(48.6)$ & 1 & $19.15(<0.001)$ \\
\hline $\begin{array}{l}\text { No supplemental feeding } \\
\text { with formula }\end{array}$ & $0(0)$ & $6(17.1)$ & 1 & $6.56(0.025)$ \\
\hline Infant ART prophylaxis & $0(0)$ & $28(80.0)$ & 1 & $46.67(<0.001)$ \\
\hline
\end{tabular}

In Table 4, it is shown that the TBAs' overall mean PMTCT of HIV knowledge score was 14.8 $\pm 11.5 \%$ prior to their training. This improved to $68.8 \pm 12.5 \%$ after post-training. The Wilcoxon signed rank test, used to assess the improvement in knowledge following the indicated that there was a high statistical significant difference between the TBAs' pre and post training mean knowledge of PMTCT of HIV, $(Z=-5.2 ; P<0.001)$.

As shown on Table 5, grading of the knowledge showed that at baseline, none of the TBAs had adequate HIV/PMTCT of HIV knowledge. This improved after the training as $32(91.4 \%)$ had adequate knowledge. Similarly, there was highly significant improvement in PMTCT of HIV knowledge grade after the training $(P<0.001)$.

Table 6 shows that at baseline, 16 (45.7\%) TBAs reported that it was their usual practice to ask about clients the HIV status and would recommend HCT for those of them who had not been previously tested in their present pregnancy. Three $(8.6 \%)$, TBAs reported that they would always counsel their clients on HIV; 6
$(17.1 \%)$, were recommending that spouses of their clients goes for HCT and another $6(17.1 \%)$, had discussed PMTCT of HIV with their clients. Referral of HIV positive clients to the health facility to access PMTCT of HIV was practiced by $10(28.6 \%)$. After the intervention, more than $75 \%$ were practicing each of the interventions. All the TBAs were recommending HCT for their clients, counselled and discussed MTCT with them. Requesting that spouses of their clients should go for HCT was practiced by $27(77.1 \%)$, TBAs while only $1(2.9 \%)$ was not referring her clients to access PMTCT of HIV services in the health facility. There was high statistical significant improvement in their PMTCT of HIV practices for all the variables following the training $(P<0.001)$.

The values shown on Table 7 were extracted from TBAs records and records in a health facility where the TBAs were referring their clients to access PMTCT of HIV services. From the TBAs records, 129 pregnant women were cumulatively referred but 52 of them complied with the referral. This gave a compliance rate of $40.3 \%$.

Table 4. Effect of training on TBAs' knowledge of PMTCT of HIV

\begin{tabular}{llll}
\hline Statistic & \multicolumn{2}{c}{ Overall knowledge } & $\begin{array}{l}\text { Wilcoxon signed } \\
\text { ranked test }(\mathbf{Z})\end{array}$ \\
\cline { 2 - 3 } & $\begin{array}{l}\text { Before training } \\
\mathbf{N = 3 5}\end{array}$ & $\begin{array}{l}\text { After training } \\
\mathbf{N}=\mathbf{3 5}\end{array}$ & \\
\hline Mean score & $14.8 \% \pm 11.5 \%$ & $68.8 \% \pm 12.5$ & $-5.2(P<0.001)$ \\
Minimum score & $0 \%$ & $48.3 \%$ & \\
Maximum & $41.4 \%$ & $96.6 \%$ & \\
\hline
\end{tabular}

Table 5. Grading of TBAs PMTCT of HIV knowledge

\begin{tabular}{llll}
\hline Knowledge grade & \multicolumn{2}{c}{ Training } & \multirow{2}{*}{$\boldsymbol{X}^{2}$ test (P-value) } \\
\cline { 1 - 3 } Grading of knowledge & Before N 35 (\%) & After N 35 (\%) & \\
\cline { 1 - 3 } Inadequate knowledge & $35(100)$ & $3(8.6)$ & \multirow{2}{*}{$54.5(<0.001)$} \\
Adequate Knowledge & $0(0)$ & $32(91.4)$ & \\
\hline
\end{tabular}


Table 6. Effect of training on the TBAs' practice of PMTCT of HIV

\begin{tabular}{|c|c|c|c|c|}
\hline \multirow{2}{*}{$\begin{array}{l}\text { Components of PMTCT OF HIV } \\
\text { practiced }\end{array}$} & \multicolumn{2}{|c|}{ Intervention } & \multirow[t]{2}{*}{ df } & \multirow[t]{2}{*}{$X^{2}(P$-value $\left.)\right]$} \\
\hline & $\begin{array}{l}\text { Before } \\
\text { intervention } \\
\mathrm{N}=35(\%)\end{array}$ & $\begin{array}{l}\text { After } \\
\text { intervention } \\
\mathrm{N}=35(\%)\end{array}$ & & \\
\hline Recommends HCT for clients & $16(45.7)$ & $35(100)$ & 1 & $26.1(<0.001)$ \\
\hline Requests to know the HIV status of client & $16(45.7)$ & $34(97.1)$ & 1 & $22.7(<0.001)$ \\
\hline Counsels client & $3(8.6)$ & $35(100)$ & 1 & $59.0(<0.001)$ \\
\hline $\begin{array}{l}\text { Requests that clients spouse should get } \\
\text { tested for HIV }\end{array}$ & $6(17.1)$ & $27(77.1)$ & 1 & $25.3(<0.001)$ \\
\hline Discusses PMTCT of HIV with client & $6(17.1)$ & $35(100)$ & 1 & $49.5(<0.001)$ \\
\hline $\begin{array}{l}\text { Refers HIV positive clients to health } \\
\text { facilities }\end{array}$ & $10(28.6)$ & $34(97.1)$ & 1 & $35.2(<0.001)$ \\
\hline
\end{tabular}

Table 7. Pregnant women compliance referral to health facility by TBAs

\begin{tabular}{ll}
\hline Variable & Frequency/Compliance rate \\
\hline Total number of pregnant women referred to health facility & 129 \\
Total number of pregnant women who complied to referral & 52 \\
Percentage compliance to referral & $40.3 \%$ \\
\hline
\end{tabular}

\subsection{Discussion}

In conformity with the guideline for the selection and re-training of TBAs in Nigeria, all the TBAs who participated were married and aged above 30 years [18]. This is similar to the age distribution of TBAs in a study in Lagos State Nigeria [10]. As explained in a studies by Irem et al in south west Nigeria, maturity of the TBAs may have bequeathed them with some sense of responsibility as care givers, and ensured confidence and respect [11] from their clients. Their sex distribution was however different from reports in some studies in which there were both female and male TBAs [8-11,14,19]. The involvement of women alone may be attributable to socio cultural believes. Most women believe that delivery is best conducted with the assistant of women especially the older one while abhoring the assistancce of young nurses or male birth assistants [20].

Literacy level was very poor among the TBAs. Apart from one TBA who completed secondary school, all the others had no formal education. This was similar to findings of a study of TBAs in Ebonyi State, Nigeria [21] and in some other developing countries [19,22-24] but differs from studies in some sub-Saharan Africa and some other developing countries where there were more TBAs who had formal education than those without $[8-10,14,25]$. Except for one TBA, who acquired her skill following a one-year apprenticeship in a private hospital, others acquired theirs' from relations especially mother as a generational trade as reported in other literatures $[26,19]$.

In addition to their practice as TBAs, each of them had some other sources of livelihood, most common being farming. This could be because since they collect little money for the services they render to pregnant women, they may need additional source(s) to augment their income for the sustenance of their families. Their lack of formal education could explain why most of them double as subsistent farmers. Also, the community is agrarian, and in such rural areas, subsistence agriculture is usually dominated by the older women as seen in this study. It is likely that the elderly ones who were not strong enough to engage in farming activities also doubled as herbalists. Having additional trade is commonly found among TBAs [10,11]. The implication of combining their practice as TBAs with other trades is that they may not be available when their services are needed by the pregnant women, including need for referral to formal health facility to access PMTCT of HIV services. This fact was supported by a study in Tanzania in which it was reported that PMTCT of HIV promoters such as TBAs spent a lot of their time on income-generating activities to support their families rather than on PMTCT of HIV project activities [27]. On the other hand, the extra money they make by having other trades may be the reason behind the little amount of money they collect from the pregnant women, and in turn explain why the pregnant women patronize them [11]. 
The TBAs' pre-training awareness of HIV was higher than their awareness of PMTCT of HIV of HIV, a finding that was in consonance with that from some other studies [8-12,14,26]. A study in India revealed even a poorer awareness [25]. The health workers were their commonest source of information, similar to the findings of some other studies $[8,9]$. On the contrary, in a previous study of TBAs in Ebonyi State, the proportion of TBAs that had heard about HIV was less and most $(84.5 \%)$ of them got their information from their peers; [21] a source which ranked second in this study. The finding that health facility workers were the commonest source of information for the TBAs, may be as a result of previous interactions between the health facility workers and members of the community, particularly when they embark on community health outreaches. The literacy level of the TBAs, their rural place of practice and possibly their income base may be the reason why the mass media, was not one of the source of information, except for one TBA. This calls for more interactions between TBAs and formal health facility workers for education on HIV and PMTCT of HIV since most of them may not have access to the electronic and print media.

Generally, the high level of awareness of HIV/PMTCT of HIV by the TBAs before the study did not reflect on their knowledge of PMTCT of HIV. This finding was comparable to a similar study among TBAs in Lagos State, Nigeria [10]. For instance, their knowledge of the modes of HIV transmission and strategies to preventing such transmission was poor. However, they knew that unprotected heterosexual transmission of HIV is the commonest mode of transmission. One surprising finding in this study was that majority of the TBAs did not know that abstaining from unprotected sex is preventive measure against HIV transmission despite knowing that unprotected sex is a mode of transmission. This may be culturally mediated since most of the TBAs were married and it may be impossible in their settings for a married woman to refuse her husband sex or demand the use of condom. This may also be because of the low status of women in our society and their weakness in negotiating safe sex with their partners. Furthermore, this thought was supported by studies which have showed that couple abstinence from sexual intercourse during pregnancy and breastfeeding increases risky behaviour for HIV transmission in the male partners $[28,29]$.

Despite the training, there was no significant improvement in knowledge of transmission through blood transfusion. This is similar to a finding of a baseline study of TBAs before their training in South Western Nigeria [11]. Other encouraging findings of the training was the significant improvement in knowledge that seeking good ante natal care (ANC) in health facility and access to PMTCT of HIV services such as hospital delivery by HIV positive pregnant women and compliance to anti retroviral therapy (ART), including infant ART prophylaxis, reduces the risk of HIV transmission.

Vertical transmission during pregnancy was most mentioned period of MTCT of HIV by the TBAs before their training in this study and in a study involving TBAs in Uganda, [30] in contrast to breastfeeding that was the most commonly known in similar studies in Nigeria [9] and Tanzania [30] respectively. The TBAs however, seemed to shy away from accepting the knowledge of risk of MTCT of HIV in some activities involving the act of delivering babies before their training. For instance, they did not accept that a pregnant woman would opt for elective Caesarean section (C/S), probably because of the misconception that pain of labour is a test of womanhood and normal vaginal delivery was seen as a natural process that should be acceptable to every woman. Some may have the erroneous perception that women who opt for C/S are weaklings while others may be afraid of complications of death associated with surgery [31-35].

It may also be explained that for fear of being put out of business, the TBAs believed that they have the skills for good management of labour and with their experience they know when to ask a woman to bear down. This may be a constraint to referral of their pregnant clients to the health facility to access PMTCT of HIV services especially when they come to them in labour, without minding the HIV status of such client.

Before the training, the TBAs recognized that HIV could be transmitted through sharing of sharps, avoidance of such practices as a measure for MTCT of HIV risk reduction was however not known to majority of them. This is an important finding which calls for reenforcement of training and re-training of the TBAs. Bearing in mind that their practices also involve cutting of cord, circumcision and giving episiotomies, there is a possibility of their using these contaminated sharps like razor blades and scissors on several individuals without prior sterilization. 
The relative difference in knowledge became more obvious on computation of the TBAs composite percentage score for PMTCT of HIV knowledge before and after the training. Extremely low knowledge of HIV/PMTCT of HIV was seen among the TBA before the training and may have been because of their overwhelming level of illiteracy. Studies have shown that training of highly illiterate respondents to get them involved in dissemination of HIV information or provide high quality care can be a challenge because of their tenacity in holding on to traditional practices or their inadequate knowledge of HIV related issues [36].

Notwithstanding, the knowledge acquired during the training enabled the TBAs to take up some correct PMTCT of HIV practices that were within their scope as TBAs, considering their mandate in the study. One hundred percent of the TBAs adopted such practices as counseling their clients on HIV/PMTCT of HIV and recommending HCT as well as discussing MTCT with them. This was at variance with the finding in the study of TBAs in South Western Nigeria in which the practices of HIV counseling and referral of pregnant women for HIV testing were poor, a situation that was attributed to low PMTCT of HIV knowledge status of the TBAs [9].

Findings from this study revealed that a total of 129 pregnant women visited the TBAs during the study period all of whom were referred to the health facility to access HCT/PMTCT of HIV services. Fifty two of them (40.3\%) complied with the TBAs referral. This is an appreciable level of compliance. However, compliance by less than half of the referred pregnant women may be because the involvement of the TBAs discouraged the pregnant women, for fear of revealing their HIV status especially as the TBAs live among them. This underscores the significance of emphasizing the importance of maintaining confidentiality and preventing stigma and discrimination if pregnant women would comply to TBAs referrals to the health facility [12]. The implication of this finding is that if this model of training and using TBAs for PMTCT of HIV services were to be adopted, efforts should be made to re-emphasize the assurance of confidentiality among the TBAs when dealing with their clients.

Noteworthy also is the fact that none of the TBAs accompanied the referred client to the health facility. Cost of transportation and other family engagements such as farming, may be constraints.

\section{CONCLUSION}

Findings from this study support the recommendation of the Nigerian National Guideline on PMTCT of HIV in which the training of TBAs on HIV/PMTCT was seen as an important means of scalling up PMTCT uptake aimed at achieving the goal of the national PMTCT plan 2012 -2015. Training the TBAs improved their knowledge and equiped them with the skill to moblize pregnant women to access PMTCT of HIV services at a formal health facility. The study also underscored the imperative of collabortive work between the informal and formal health sectors in efforts to achieve the World Health Organization's (WHO) strategic vision $2010-2015$ which has the vision and goal of having women/children alive and free of HIV and to eliminate paediatric HIV infections and improve maternal/child health and survival in the context of HIV respectively. The study also revealed that investing resources in the training of TBAS on PMTCT of HIV and their use in HIV counseling and mobilizing pregnant women may bring a significant proportion of their pregnant clients to the health facilities to access PMTCT of HIV services. This will significantly reduce MTCT of HIV as well as the disease burden in the society. Compliance to referral may increase further if training and retraining of TBAs is reenforced as such training would further build the capacity of the TBAs to give accurate information on HIV/PMTCT of HIV and sound counselling to the pregnant women; practices that would encourage acceptance of referral.

\section{CONSENT}

Permission was obtained in the form of a written informed consent, which was signed by the traditional ruler of the study area. The participating TBAs also signed or thumb printed a consent form. The participants were also assured that all information they gave shall be treated with confidentiality.

\section{ETHICAL APPROVAL}

Ethical clearance for this study was obtained from the Research and Ethics Committee of Ebonyi State University Teaching Hospital now Federal Teaching Hospital Abakaliki. 


\section{COMPETING INTERESTS}

Authors have declared that no competing interests exist.

\section{REFERENCES}

1. UNAIDS/NACA. United Nations General Assembly Special Session (UNGASS), country progress report; Nigeria. Reporting period: January 2008-December 2009. Nigeria: NACA. 2010;37.

2. WHO/UNAIDS. AIDS epidemic update December 2007. Joint United Nations Programme on HIV/AIDS (UNAIDS) and World Health Organization (WHO). 2007;8.

3. WHO/UNICEF/UNAIDS. Towards access; scaling up priority HIV/AIDS interventions in the health sector. Progress report 2009. Geneva: WHO. 2009;89.

4. Federal Ministry of Health. National guidelines for prevention of mother-to-child transmission of HIV. Abuja: FMoH. 2010; 52.

5. USAID/NACA/FMOH. Nigeria HIV/AIDS. Service provision assessment 2008. Abuja: FMoH. 2008;76.

6. Federal Ministry of Health. Saving newborn lives in Nigeria: Newborn health in the context of the Integrated Maternal, Newborn and Child Health Strategy. $2^{\text {nd }}$ edition. Abuja: Federal Ministry of Health, Save the Children, Jhpiego. 2011;19.

7. Imogie $\mathrm{AO}$, Agwubike $\mathrm{EO}$, Aluko $\mathrm{K}$. Assessing the role of traditional birth attendants (TBAs) in health care delivery in Edo State, Nigeria. African Journal of Reproductive Health, 2002;6(2):94-100.

8. Bassey EB, Elemuwa $\mathrm{CO}$, Anukam KC. Knowledge of, and attitudes to, acquired immune deficiency syndrome (AIDS) among traditional birth attendants (TBAs) in rural communities in Cross River State, Nigeria. International Nursing Review. 2007;54:354-358.

9. Mobolanle B, Kofoworola O. Knowledge and practice of prevention of mother-tochild transmission of HIV among traditional birth attendants in Lagos State, Nigeria. Pan Afr Med J. 2010;5:7.

10. Ahmed O, Odunukwe N, Raheem Y, Efienemokwu C, Junaid M, Adesesan S, Ogedengbe $\mathrm{O}$, Harry $\mathrm{T}$, Salako $\mathrm{L}$. Knowledge, attitudes and perceptions of HIV/AIDS among traditional birth attendants and herbal practitioners in
Lagos State, Nigeria. African Journal of AIDS Research. 2004;3(2):191-196.

11. Inem V, Kanu R, Atere A. Baseline knowledge, practice and experience of TBAs on HIV/AIDS before commencement of training on PMTCT of HIV of HIV in south west Nigeria. Nigerian Medical Practitioner. 2008;53(6):103-109.

12. Perez F, Aung KD, Ndoro T, Engelsmann $B$, Dabis F. Participation of traditional birth attendants in prevention of mother-to-child transmission of HIV services in two rural districts in Zimbabwe: A feasibility study. BMC Public Health. 2008;8:401.

DOI: 10.1186/1471-2458-8-401.

13. Wanyu B, Diom E, Mitchell $P$, Tih PM, Meyer DJ. Birth attendants trained in "Prevention of mother-to-child HIV transmission" provide care in rural Cameroon, Africa. Journal of Midwifery \& Women's Health. 2007;52(4):334-341.

14. Mobolanle B, Kofoworola O, Folasade O, Sylvia A. HIV/AIDS training of traditional birth attendants in Southwest Nigeria. Journal of Medicine and Biomedical Sciences. 2012;3(1). ISSN: 2078-0273.

15. World Health Organisation Office, Ebonyi State, Nigeria. WHO; 2010.

16. United Nations Population Fund. Country programme of assistance to Nigeria; End line/baseline survey: Questionnaire for health facilities. UNFPA; 2008.

17. SPSS 16.0 for Window. Statistical package for social scientists incorporated, Version 16: Polar Engineering and Consulting; 2007.

18. Amosu AM, Degun AM, Makinde CM, Thomas AM, Babalola AO. An assessment of specific knowledge and attitude of health care providers towards people living with HIV/AIDS in Ibadan, Nigeria. Annals of Biological Research, 2012(2):255-264.

19. Federal Ministry of Health. Guideline and training manual for the development of primary health care system in Nigeria. Lagos, FMoH. 1990;16-17.

20. Reasons for home delivery and use of traditional birth attendants in rural Zambia: A qualitative study. BMC pregnancy and childbirth. 2015;15:216.

21. Isenalumbe AE. Integration of traditional birth attendants into primary health care. World Health Forum. 1990;11:192-198.

22. Ejikeme BN, Umeora OU, Obuna JA. HIV/AIDS: Awareness and practice among traditional birth attendants in Rural Nigeria. 
The Nigerian Medical Practitioner, 2007; 51(1\&2):6-10.

23. Thatte N, Mullany LC, Khatry SK, Katz J, Tielsch JM, Darmstadt JL. Traditional birth attendants in rural Nepal: Knowledge, attitudes, and practices about maternal and newborn health. Global Public Health. 2009;4(6):600-617.

24. Falle TY, Mullany LC, Thatte N, Khatry SK, LeClerq SC, Darmstadt GL, Katz J, Tielsch JM. Potential role of traditional birth attendants in neonatal healthcare in rural Southern Nepal. J Health Population Nutrition. 2009;27(1):53-61.

25. Madhivanan $\mathrm{P}$, Kumar BN, Adamson $\mathrm{P}$, Krupp K. Traditional birth attendants lack basic information on HIV and safe delivery practices in rural Mysore, India. BMC Public Health. 2010;10:570.

DOI: 10.1186/1471-2458-10-570

26. Rujumba1 J, Tumwine JK, Tylleskär $\mathrm{T}$, Neema S, Heggenhougen HK. Listening to health workers: Lessons from Eastern Uganda for strengthening the programme for the prevention of mother-to-child transmission of HIV. BMC Health Services Research. 2012;12:3.

27. Orne-Gliemann J, Mukotekwa T, Perez1 F, Miller E, Sakarovitch C, GlenshawM, Engelsmann B, Dabis F. Improved knowledge and practices among end-users of mother-to-child transmission of HIV prevention services in rural Zimbabwe. Tropical Medicine and International Health. 2006;11(3):341-349.

28. Taiwo O. Lawoyin AL, Ulla L. Male sexual behaviour during wife's pregnancy and post-partum period in Oyo State. Journal of Biosocial Science, 2002;34(01):51-63.

DOI:http://dx.doi.org/DOI:10.1017/S00219 32002000512

29. Harms G, Schulze K, Moneta I, Baryomunsi C, Mbezi P, Poggensee $G$. Mother-to-child transmission of HIV and its prevention: awareness and knowledge in
Uganda and Tanzania. Journal of Social Aspects of HIV/AIDS. 2005;2(2):258-266.

30. Keating M, Hamela G, Miller WC, Moses A, Hoffman IF, Hosseinipour MC. High HIV incidence and sexual behavior change among pregnant women in Lilongwe, Malawi: Implications for the Risk of HIV Acquisition; 2012.

DOI: 10.1371/journal.pone.0039109

(Accessed June 7, 2015)

31. Keating M, Hamela G, Miller WC, Moses A, Hoffman IF, Hosseinipour MC. High HIV incidence and sexual behavior change among pregnant women in Lilongwe, Malawi: Implications for the Risk of HIV Acquisition; 2012.

DOI: 10.1371/journal.pone.0039109 (Accessed June 7, 2015)

32. Naithani U, Bhawal P, Chauhan SS, Kumar D, Gupta S, Kirti. Knowledge, attitude and acceptance of antenatal women toward labor analgesia and caesarean section in a medical college hospital in India. Journal of Obstetrics Anaesthesia and Critical Care. 2001;1(1): 13-20.

33. Adageba RK, Danso KA, Adusu-Donkor F. Awareness and perceptions of and attitudes towards caesarean delivery among antenatal. Ghana Medical Journal. 2008;42(4):137-140.

34. Angeja AC, Washington AE, Vargas JE, Gomez R, Rogas I, Caughey AB. Chilean women's preferences regarding mode of delivery: Which do they prefer and why? British Journal of Gynaecology. 2006; 113(11):1253-1258.

35. Aziekn M, Omo-Aghoja L, Okonofua F. Perceptions and attiturdes of pregnant women towards caesarean section in urban Nigeria. Acta Obstet Gynecol Scand. 2007;86(1):42-47.

36. Qazi Q, Akhtar Z, Khan K, Khan $\mathrm{AH}$. Pregnant women view regarding cesarean section in Northwest Pakistan. Trop Med Surg. 2013;1:105.

(c) 2017 Una et al.; This is an Open Access article distributed under the terms of the Creative Commons Attribution License (http://creativecommons.org/licenses/by/4.0), which permits unrestricted use, distribution, and reproduction in any medium, provided the original work is properly cited.

Peer-review history:

The peer review history for this paper can be accessed here: http://sciencedomain.org/review-history/19970 